\title{
Os Desafios da Formação do Professor para Educação de Surdos
}

\author{
Leliane Aparecida Castro Rocha*
}

\section{Resumo}

Neste capítulo, buscamos fazer uma reflexão a respeito da formação de professores que atuam com a educação inclusiva para surdos. Nossa preocupação direciona-se para uma inclusão escolar com qualidade. A língua brasileira de sinais - Libras, é um instrumento de comunicação e afirmação da identidade da pessoa surda. Há desafios desde a formação do professor até sua atuação em sala de aula. O que nos motivou à realização deste texto foi a necessidade de refletirmos sobre uma educação de surdos que desenvolva em seu currículo a possibilidade de contemplar elementos que fortaleçam a sua identidade. São necessárias escolas preparadas para atender à realidade do surdo e uma comunidade escolar interativa com o compromisso e comprometimento de todos pela educação, desde os níveis centrais até a sala de aula inclusiva.

Palavras-chave: Formação de Professor. Educação de Surdos. Educação Inclusiva. Libras

\section{The Challenges in the Formative Process of Teachers for the Education of the Deaf}

\section{Abstract}

In this chapter we seek for a reflection about the teacher training that work with inclusive education for the deaf. Our worry is aimed to a school inclusion with quality. The Brazilian Language of Signs - Libras, is an

* Doutoranda em Educação no Programa de Pós-Graduação em Educação da Universidade Metodista de São Paulo. Mestre em Semiótica, Tecnologia da Educação e Educação - UBC. Especialista em Língua Brasileira de Sinais Libras - Unicid. Professora Universitária no Centro Universitário São Judas - Campus Unimonte, e no Centro Universitário Salesiano - Campus Santa Teresinha. Vice-coordenadora intérprete da Pastoral do Surdo no Santuário Nossa Senhora do Sagrado Coração - Vila Formosa/SP. 
instrument of communication and affirmation of identity of the deaf person. There are challenges for the teacher since the formative process until performing activities in the classroom. What motivated us to write this text was the necessity of reflecting about an education of the deaf which enables one's identity in one's resumé. It is necessary for schools to be prepared to assist the reality of the deaf, and to have an interactive school community with the compromise and commitment of all for education, since the central until the inclusive classroom.

Keywords: Teacher Training. Education of the Deaf. Inclusive Education. Libras

\section{El Desafío de Formación del Profesor para Educación de Sordos}

\section{Resumen}

En este capítulo, buscamos hacer una reflexión acerca de la formación de profesores que atañen con la educación inclusiva para sordos. Nuestra preocupación se dirige hacia una inclusión escolar con calidad. La Lengua Brasileña de Signos - Libras, es un instrumento de comunicación y afirmación de la identidad de la persona sorda. Hay desafíos desde la formación del profesor hasta su actuación en el aula. Lo que nos motivó la realización de este texto fue la necesidad de reflexionar sobre una educación de sordos que desarrolle en su currículo la posibilidad de contemplar elementos que fortalezcan su identidad. Se necesitan escuelas preparadas para atender la realidad del sordo y una comunidad escolar interactiva con el compromiso y compromiso de todos por la educación, desde los niveles centrales hasta el aula inclusiva.

Palabras-clave: Formación de Profesor. Educación de Sordos. Educación Inclusiva. Libras

\section{Os Desafios da Formação do Professor para Educação de Surdos}

Uma nova civilização emerge neste início do século XXI, e com ela, modos diferentes de trabalhar e viver, conflitos políticos, econômicos e sociais, que levam a questionar a qualidade da formação do profissional em Libras.

Essa nova civilização sinaliza um novo código de comportamento para além da padronização, sincronização e centralização. 
Cabe aos educadores encontrar alternativas para esta mudança de paradigma, que implica um repensar geral do desempenho do professor de Libras em sala de aula no ensino superior, e sem dúvida em todos os níveis de ensino.

Neste contexto ora delineado, nossa preocupação direcionouse para a inclusão escolar, a qual está inserida em um movimento mundial denominado inclusão social - e, por conseguinte, tudo nos leva a refletir sobre a evolução do conhecimento, sem deixarmos de lado as variáveis de indivíduo para indivíduo, de lugar para lugar e de época para época. Se olharmos para o retrovisor da história da humanidade, temos ainda que reconhecer que nenhuma instituição esteve tão presente, no campo da Educação, quanto a igreja.

Estudamos Santo Agostinho, que defendia que os surdos deveriam e poderiam aprender, e transmitir algum conhecimento por meio dos gestos, que seriam equivalentes à fala, e com isso alcançar a salvação da alma. Dentro da igreja iniciou-se a tentativa de comunicação e educação com surdos. Claro que não estamos falando da língua de sinais que conhecemos hoje (CARVALHO, 2007).

Devemos valorizar, também, o que foi realizado pelo monge beneditino Pedro Ponce de León, em Oña, Espanha, considerado o primeiro professor de surdos. Ele dedicou-se a ensinar surdos, filhos de nobres, pois, as pessoas que não conseguissem falar não tinham quaisquer direitos perante a lei. Portanto, educavam-se os primogênitos para que pudessem herdar a fortuna da família.

Segundo Carvalho (2007), Pedro Ponce de León desenvolveu um tipo de alfabeto para fazer com as mãos, que ele criou com o intuito de soletrar as palavras, e assim manter o voto de silêncio dos monges, o que favoreceu o uso com surdos.

Com base nos gestos que os surdos já conheciam, Abade de L'Épée, ensinava a escrita, mas não considerava uma língua com gramática, pois a estrutura da escrita era a mesma utilizada pela língua oral do seu idioma - o francês. Deste modo, quando ditado em língua gestual, os alunos conseguiam ler e escrever quaisquer palavras ou textos inteiros, em francês com a gramática correta (CARVALHO, 2007). 
Muitos dos professores de surdos eram oralistas, afirmavam que mesmo tendo imposto a língua oral aos surdos de toda e qualquer forma possível, reconheciam que a língua gestual era a língua principal, ou seja, a materna das pessoas surdas.

Com tantas tentativas de ensinarem aos surdos a língua oral, eis que em 1880 aconteceu o Congresso de Milão, onde grupos de ouvintes e educadores de surdos decidiram excluir toda e qualquer tentativa de comunicação por gestos. Sendo os surdos obrigados a abandonar sua língua materna em prol da oralização.

Defendiam seus posicionamentos, dizendo que o uso simultâneo da língua oral e da língua gestual traria desvantagens, pois se usassem mais a gestual, ficaria em segundo plano a fala, e afetaria seu desenvolvimento.

O sacerdote, diretor da escola de surdos de Milão, e também ouvinte, Giulio Tarra, presidiu e coordenou o Congresso de Milão (1880). Com todo o seu entusiasmo oralista, encerrou os trabalhos do evento dizendo: "Ontem estávamos a desejar longa vida ao oralismo! Agora podemos dizer, longa vida ao Oralismo Puro!" (CARVALHO, 2007, p. 68).

Para ele, a aplicação do método oral puro, nas escolas era necessário, e deveriam separar as crianças que já sabiam se comunicar com gestos, para não prejudicar a aprendizagem dos que iriam iniciar-se nas escolas. Assim, gradativa e progressivamente a instrução através da fala poderia se consolidar.

Por muito tempo, os surdos ricos eram atendidos por professores, médicos, fonoaudiólogos e cuidadores, para que pudessem aprender a língua oral (orofacial), para se manterem herdeiros, porém a grande maioria permanecia à margem da escolarização básica.

O povo surdo foi narrado através da representação da invalidez [...] As modalidades enunciativas do historicismo fazem o surdo narrado, sobre determinado como mito, como elemento inútil, sem vida. Os rumos desse historicismo não vão iniciar mudanças com o reconhecimento da língua de sinais. Nem muda de sobremodo com a introdução da língua de sinais na educação (PERLIN, 2003, p.47). 
Durante séculos, procuraram-se os melhores caminhos para educar os surdos. Professores, médicos, fonoaudiólogos, psicólogos, vários religiosos, entre outros, e todos defendiam as suas técnicas e métodos para a instrução dos surdos, que eram visivelmente considerados inferiores às pessoas ouvintes. Não por falta de capacidade cognitiva, mas por falta de uma boa comunicação, sendo sempre discriminados e marginalizados, sendo proibidos, em muitos casos, seu acesso à escolarização e ao convívio social. Por isso, muitas famílias escondiam os seus deficientes.

Em 1994, na conferência mundial da UNESCO sobre as necessidades educacionais especiais, circulou a seguinte mensagem a todos: A educação é uma questão de direitos humanos, e os indivíduos com deficiências devem fazer parte das escolas, as quais devem modificar seu funcionamento para incluir todos os alunos.

Portanto, a defesa da educação de surdos no Brasil, ficou marcada por Brito (1996), pesquisadora e linguista, que explicou e sistematizou as formas gramaticais utilizadas pela língua de sinais brasileira. As pessoas que convivem com surdos foram as primeiras a subsidiá-la com informações para a identificação e organização da língua utilizada pelos surdos brasileiros.

\section{Os caminhos da inclusão dos surdos}

No Brasil viveu e vive-se uma história de perdas, de exclusões e de manutenção de privilégios de minorias, caracterizada pela opressão, pela carência, pelo descrédito e ausência de perspectivas que a estrutura e o funcionamento educacional apontam ainda hoje para o processo de inclusão - destacando-se aqui os surdos.

Conforme Delors (1998, p. 49) "[...] compreender os outros faz com que cada um conheça melhor a si mesmo”. Deste modo, incluir a todos é sempre um buscar pelo conhecimento e autoconhecimento.

$\mathrm{O}$ atendimento educacional das pessoas deficientes, o que inclui o surdo, é assegurado pela Constituição da República Federativa do Brasil (1988, art. 205 e 208), na medida em que 
considera direito de todos, bem como a Lei de Diretrizes e Bases da Educação Nacional - LDBEN (1996), que traz em sua ideologia uma escola para todos, reforçando o já assegurado na Constituição citada. E dessas legislações, surge outra, em prol dos surdos, que é a Lei n. 10.436, sancionada pelo presidente Fernando Henrique Cardoso, em 24 de abril de 2002, reconhecendo legalmente como meio de comunicação e expressão, a Língua Brasileira de Sinais - Libras, por entender que é um sistema linguístico de natureza visual-motora, com estrutura gramatical própria das pessoas surdas do Brasil.

Seguindo essas legislações, surge o Decreto n. 5626, de 22 de dezembro de 2005, no seu Capítulo II, art. $3^{\circ}$ - que determina a inclusão da Libras como disciplina curricular obrigatória em cursos de formação de professores, fonoaudiologia e educação especial, e disciplina optativa para demais cursos. No entanto, não está pre-determinada e explícita a quantidade de carga horária para esta disciplina, o que em muitos casos prejudica a comunicação e interação do professor com o aluno surdo.

Deste modo, a investigação e a verificação dos cursos de Formação de Professores e Licenciaturas em Instituições de Ensino Superior - IES, particulares, da cidade de São Paulo se fizeram necessárias, como orientado no Decreto n. 5626 de 2005. Assim, surgiu a preocupação da pesquisadora em mostrar como os futuros professores desses cursos estão sendo preparados para receber os surdos, e trabalhar com eles em sala regular.

Reconhecendo que a Língua Brasileira de Sinais - Libras, é a língua materna do surdo, considerada sua primeira língua, aqui determinada como L1, e a língua portuguesa sua segunda língua, a L2. Para os ouvintes, o processo é proporcionalmente inverso.

No entanto, analisar os subsídios que as universidades estão oferecendo à formação em Libras para esses profissionais para se comunicarem com os surdos, ou pelo menos entender sua forma de aprendizagem, e tornar possível a educação formal em sala regular, esse é o grande desafio da atualidade. 
O estudo das formas de comunicação dos surdos na sociedade contemporânea e o da comunicação dos professores com os alunos são fundamentais para compreensão dos sujeitos. É importante registrar que não se pode lutar pela implementação de algo que não se conhece e, ao discutir o problema, os envolvidos devem ter consciência do que estão fazendo (ROCHA, 2017, p. 76).

Sabemos que não basta a escola ter normas e regras, que regulem os comportamentos de todos, pois se fazem necessários o diálogo e o comprometimento de todos. A sala de aula será sempre um lugar de grandes e eternos desafios. O cotidiano escolar permite que os papéis sociais sejam construídos, e nesse aspecto, a escola torna-se fundamental para a sociedade.

Ao respeitarmos o seu modo de comunicação e vivência, compreendemos e oportunizamos seu ingresso de pertencimento na escola. A sala de aula tende a se tornar inclusiva pelo compromisso e disponibilidade para acompanhar e analisar os modos complexos do conviver, ou seja, do todo e de todos.

Para praticar a inclusão, não é apenas modificar o funcionamento de um local, mas os olhares para todos aqueles que estão inseridos no processo educacional, sem exceção, ou seja, toda a equipe deve ser acolhida por todos em todas as situações.

Como já afirmava Moura (2000), somos todos produto da História, e o que ela produz e reproduz em cada um de nós. Isso nos leva a defender que todo indivíduo, ao se descobrir, compreender sua realidade, se considerando diferente, porém com possibilidades de integração e transformação, se torna único e protagonista de sua vida, articulado com o mundo que o cerca.

Diante disso, é necessário considerar os desafios que, diariamente, os sujeitos se deparam no âmbito escolar. Assim, é possível compreender a realidade da comunidade surda, e com isso ajudar a construir uma identidade própria que reflita os seus atores - os surdos.

Isso posto, são inúmeras as variáveis a serem consideradas - a comunidade, os alunos, os professores, os gestores, a política 
educacional e tantas outras que ora dificultam e ora facilitam o processo de transformação das práticas cotidianas. $O$ que vale ressaltar é que a escola só existe em função dos discentes. Eles são a base de tudo, o que nos faz acreditar que é possível sempre fazer diferente, para que o processo seja o melhor possível sempre.

Podemos dizer que incluir o surdo não é apenas colocá-lo em sala de aula, ou colocá-lo e disponibilizar junto a ele um intérprete. Vai muito além, é comprometimento pessoal e atitudinal diário, de todos que participam do processo educacional de inclusão. É por meio do currículo que a construção de identidade cultural e social, irá construir a identidade individual do aluno surdo ou não.

Um dos caminhos para construir sua identidade, muitas vezes, se faz pela língua. Há diversos estudos sobre as várias formas de comunicação de surdos e seus professores, mas na maioria das vezes prevalece a forma de comunicação de seus professores, que normalmente são ouvintes e oralistas. Porém, a sociedade contemporânea tende a promover o inverso, ou seja, o aluno no centro da relação. Isso ocorre com todo tipo de alunado, porém, quando se trata de alunos surdos, essa centralização nem sempre ocorre.

Os surdos, por muito tempo, foram considerados incapazes de aprender, pois eram classificados como retardados. Segundo Lacerda (2000), alguns surdos têm som, porém sem pronúncia das palavras como os oralistas compreendem. Temos que reconhecer que não podemos falar de desenvolvimento, se os indivíduos não estiverem inclusos em uma ação constante de construção e reconstrução de seus saberes.

As considerações sobre as ações dentro ou fora da escola, procedem de movimento de vaivém entre os ideais e os modos de pensar as vantagens ou não vantagens das escolhas que fazemos, que define o percurso de nossa vida e, por isso, favorecer a tomada de decisões sobre o futuro que queremos seguir (REILY, 2009).

A relevância social desta temática se sustenta pela contribuição de refletirmos sobre o entendimento, e pela percepção dos possíveis 
caminhos a enfrentarmos em direção à inclusão. A propósito, não é pecado algum ter dúvidas sobre a viabilidade da inclusão. Há varias lentes para se pensar em uma sociedade inclusiva pelas várias e diferentes razões. O que vale a pena é que a escola só existe em função dos alunos. Sendo eles a base de tudo, há necessidades sociais e culturais próprias que, neste caso, é a língua. Toda língua se faz presente em todos os cantos do mundo, e também as línguas de sinais.

Um esforço de inclusão social e cultural por parte da sociedade, na tentativa de melhor compreender a comunidade surda, sua trajetória e suas necessidades ainda está longe do ideal. Porém, é preciso a conscientização de que somos todos responsáveis pela qualidade de ensino que oferecemos, em prol do desenvolvimento escolar e profissional dos surdos.

Com isso, partimos do pressuposto de que a escola é um bem público e um direito de todos. Não somente um espaço burocrático, mas um ambiente de relações humanas. Evidente que essa mudança de olhar não é fácil, mas é necessária.

Devemos considerar que não é uma simples mudança extrínseca, e sim, intrínseca e complexa, que precisa partir da conscientização e reconhecimento da própria humanidade.

Atualmente, há vários discursos sobre inclusão, e verificamos que incluir não é apenas um processo burocrático, mas uma sequência de ações praticadas dentro e fora dos muros escolares.

Incluir um aluno surdo em uma escola regular é mais que ter um intérprete ou um interlocutor em sala, é um trabalho com todos os membros escolares, desde a direção até as pessoas que visitam este ambiente.

Voltamos à premissa que a escola é para todos, e que todos são capazes de aprender, e que não se aprende fragmentando disciplinas e pessoas. Como diz Morin:

[...] a inteligência que só sabe separar fragmenta o complexo do mundo em pedaços separados, fraciona os problemas, unidimensionaliza o multidimensionamento. Atrofia as possibilidades de compreensão e de reflexão, eliminando assim as oportunidades de um julgamento corretivo ou de uma visão a longo prazo (MORIN, 2002, p.14) 
Os problemas auditivos podem estar presentes em qualquer idade, raça, classe social, e não raro, a surdez adquirida por inúmeros motivos desde um acidente até o uso abusivo dos altos sons em fones de ouvidos.

Em suma, proponho olhar a surdez e os surdos não pela falta, mas por aquilo que ela marca como diferente. A surdez, antes de qualquer outra diferenciação que possa ser estabelecida, chama a presença do som para o contraponto. Não aproxima o som para que uma relação de oposição se estabeleça, mas para que uma relação de diferenciação tenha condições de se colocar (LOPES, 2007, p. 23).

As políticas públicas vêm abordando a noção de diferença para contemplar os currículos pensados para os sujeitos, os quais se encontram nos discursos da educação inclusiva, e os alunos surdos não fogem a essas normas.

Para buscar a ordem e manter a tranquilidade dos demais, é preciso continuar demarcando as linhas divisórias e as balizas entre nós - os normais, os capacitados, os iguais - e eles - os anormais, os diferentes, os descapacitados. No entanto, essa demarcação de território vê-se travestida sob o slogan da igualdade, da homogeneidade e da tolerância, em especial por esta última, que nos convida a aceitar e conviver com a diferença (LUNARDI, 2003, p. 182)

Discutir a respeito dessas marcas permite-nos pensar na fragilidade de tratarmos das diferenças, sobre as representações que o cenário educacional nos mostra, e essas marcas com uma nova roupagem. Porém, selecionar uma metodologia adequada para cada aluno requer uma visão histórica-crítica da realidade do indivíduo com um trabalho multidisciplinar de vários profissionais, e a participação ativa da família.

\section{A Formação do Professor na perspectiva da educação inclusiva para surdos}

Ainda hoje, a inclusão escolar tem desencadeado discussões, e seu avanço está em passos lentos e curtos, no sentido da construção de processos educacionais inclusivos e da formação de professores. 
Ao falarmos em inclusão de alunos surdos, nas salas do ensino regular, temos que considerar os aspectos ligados à formação do professor, uma vez que este deve ser preparado para o chão da escola, o seu cotidiano.

A formação de professores deverá ser concebida como um processo dinâmico, tanto coletivo como individual, independente da análise do trabalho pelos próprios sujeitos, tendo como resultado a tessitura de um conhecimento comum. Trata-se de um processo que implica investimento pessoal, um trabalho livre e criativo sobre os percursos e projetos próprios, com vista à construção de uma identidade (NÓVOA, 1995, p. 25).

$\mathrm{O}$ professor precisa estar ciente que as pessoas nunca estão prontas, que sempre nos transformamos, e até mesmo nos reinventamos quando necessário, pois todos podem ser a melhor versão de si mesmo a todo instante.

É notório que os docentes mais articulados com a sociedade, que realmente abraçam a profissão como opção, valorizam a vida do outro, percebem a atitude de não discriminação e aceitação do diferente, sem que ninguém seja bonzinho por agir assim (WERNECK, 2009).

Há necessidade de se mudar a visão do senso comum, em relação a acreditar que se a escola e o professor receberem um aluno surdo, estarão sendo generosos e bondosos, ou se tiver um intérprete presente, já é o suficiente para o processo de aprendizagem do referido aluno em salas consideradas inclusivas (WERNECK, 2009).

Temos que considerar, também, os aspectos ligados à formação do professor, uma vez que ele deve estar preparado para trabalhar com o cotidiano escolar inclusivo. Conforme nos ensina Piaget:

[...] a preparação dos professores constitui questão primordial de todas as reformas pedagógicas em perspectiva, pois enquanto não for a mesma resolvida de forma satisfatória, será totalmente inútil organizar belos programas ou construir belas teorias a respeito do que deveria ser realizado (1973, p. 62). 
Mesmo considerando, que a educação inclusiva exige do professor do ensino regular, um certo tipo de especialização para compreender as características peculiares, em uma perspectiva de um ensino de qualidade, se faz necessário o diálogo com as pessoas que convivem com a pessoa surda, a fim de contribuir e fornecer pistas para o trabalho de toda a equipe educacional, facilitando assim a aprendizagem do surdo em escolas e salas regulares.

Consideramos interessante ressaltar que, o professor precisa participar ativamente de todas as ações, opinando e discutindo com a equipe escolar e familiares, para conseguir planejar, elaborar, executar e avaliar adequadamente o surdo, oportunizando seu desenvolvimento pleno.

O interesse em saber como as IES estão formando seus futuros professores vai ao encontro do pensamento de Bueno (1999) que aponta que alguns desafios à formação são necessários, como: formação teórica sólida e adequada no que se refere aos diferentes processos e procedimentos pedagógicos, que envolvem tanto o saber como o saber fazer pedagógico. Uma formação que possibilite identificar e atuar com as mais diversas diferenças, entre elas, os surdos. Assim, como ter uma formação sobre suas características, necessidade e procedimentos pedagógicos específicos da surdez, e seus vários níveis.

Eis aí um dos desafios dos pesquisadores ouvintes ou surdos, que trabalham em consonância com as causas surdas, como é o nosso caso. Defendemos a necessidade de formação de professores que assegurem o desenvolvimento pleno de seus alunos com ou sem deficiência, com maior qualidade.

Como bem aponta Cury (2005, p. 13), ao nos dizer que “" [... reconhecendo o professor como um profissional que, consciente de seus deveres, busca sempre maior envolvimento com seu trabalho, objetivando o desenvolvimento dos seus alunos".

Para que isso possa se tornar possível, se faz necessário buscar compreender as atividades no/do cotidiano escolar. Perceber determinada realidade observando a importância em 
desenvolver a percepção sobre o ambiente escolar para significar as vivências contextualizadas com ações práticas e reflexivas envolventes. $\mathrm{O}$ viver, o sentir, o dialogar e o participar do ambiente dando condições de conhecer o real, pois precisamos ir muito além do olhar que se vê, com o qual aprendemos a trabalhar.

Uma visão dinâmica da educação, como Mazzotta (1998) defende, a de não segregação, que possibilite uma melhor compreensão da relação entre educando e educação escolar, que comporta a situação de ensino aprendizagem mais condizente com as necessidades educacionais. Alunos e escolas identificados por seus papeis sociais, e não por uma configuração individual separada e isolada de sua contextualização social e cultural.

Em entrevista com alguns dos futuros professores, os mesmos demonstraram não ter compreendido plenamente o que significa uma escola inclusiva, sem segregação, o que evidencia algumas lacunas no processo de formação, e reflexos negativos na prática docente. Não podemos generalizar, tampouco culpá-los pelos descasos da própria educação. Talvez, sem generalizar, alguns ainda não tenham compreendido o significado de 'ser professor', o que evidencia algumas lacunas os processos de formação.

Desde 2001, as Diretrizes Curriculares Nacionais para a Educação Especial na Educação Básica orientam que:

[...] os programas de formação inicial deverão incutir em todos os professores da educação básica uma orientação positiva sobre a deficiência, que permita entender o que se pode conseguir nas escolas com serviços locais de apoio. Os conhecimentos e as aptidões são as mesmas de uma boa pedagogia, isto é, a capacidade de avaliar as necessidades especiais, de adaptar o conteúdo do programa de estudos, de recorrer à ajuda da tecnologia, de individualizar os procedimentos pedagógicos para atender a um maior número de aptidões. Atenção especial deverá ser dispensada à preparação de todos os professores para que exerçam sua autonomia e apliquem suas competências na adaptação dos programas de estudos e da pedagogia, a fim de atender às necessidades dos alunos e para que colaborem com os especialistas e com os pais (MEC/SEESP, 2001, p. 17-18). 
Ressaltamos assim, a importância da formação de professores e a relevância de seu papel frente ao desenvolvimento educacional inclusivo. Fica nítida a percepção de que o professor, isolado e sozinho no processo, não construirá uma escola inclusiva, pois é uma tarefa de todos e para todos.

Parece-nos fundamental a reflexão das questões relacionadas ao processo de formação docente, para que o enfrentamento dos desafios da mudança, para incluir todos os alunos na escola sem discriminação e preconceito, sejam verdadeiramente asseguradas.

Não podemos deixar de observar que a educação envolve processos de reestruturação das mais diversas dimensões, como cultura, política, prática escolar e tantas outras, que cercam a sociedade contemporânea para atender às peculiaridades das diferenças.

Inúmeros estudos têm demonstrado que uma das barreiras para a efetivação da inclusão é o despreparo da comunidade escolar, em todos os níveis (GLAT, 2000).

Neste momento, discutimos ainda a necessidade de mudarmos nossos limites. É necessário criar uma nova organização de pensamento e novos processos, sempre observando as teorias que servem de sustentação para uma prática significativa em cada dia.

Precisamos entender o processo, como um todo, aprendido com o objetivo de reinventar um novo processo com base na aprendizagem vivenciada, sempre com uma abordagem multirreferencial de leitura plural dos objetivos práticos e teóricos, definindo as linguagens apropriadas no processo de aprender-ensinar, com capacidade de revirar em si mesmo o que está pronto e acabado.

Santos (2009), questiona como formar professores para atuar com a grande diversidade, se seus próprios mestres nem sempre lhes servem de exemplo? Como formar um professor que respeite as diferenças e as diversidades que o mundo apresenta, se ele mesmo teve suas diferenças e diversidades desrespeitadas e não contempladas? Não foi apenas com a inclusão de duas ou três disciplinas na grade curricular, que abordam a educação inclusiva, Libras e diversidades, que os cursos de licenciaturas promoveram 
uma mudança expressiva de valores, atitudes e comportamentos para a prática inclusiva.

Os currículos privilegiam determinados saberes em detrimento de outros, que à luz de Bourdieu \& Passeron (1975), explicam que é para favorecer sempre os interesses de grupos e classes dominantes, o que claramente não é o caso dos surdos.

Precisamos repensar sempre sobre a necessidade de sermos professores diferentes daqueles que nos formaram, pois ao considerarmos a escola inclusiva uma escola nova, não podemos nos apresentar como nossos antecessores.

Dessa forma, novos olhares serão necessários para o fazer acadêmico, profissional e científico. As pessoas agem e reagem em função de suas crenças, percepções, sentimentos e valores. O que significa que precisamos agir e reagir com autonomia, não apenas reproduzindo e repetir o processo. Precisamos romper com o medo do novo.

Entretanto, se olharmos, novamente, no retrovisor da História da Formação do educador no Brasil, identificaremos a tradição de uma formação inicial, básica ou profissionalizante. $\mathrm{O}$ futuro professor precisa refletir sobre a educação e sua perspectiva política, e analisar sua trajetória e ações dentro e fora da escola, romper com o paradigma de um ensino fragmentado e olhar para a educação, acreditando no sujeito que constrói a sua história, da qual faz parte.

De uma maneira mais abrangente de nos posicionarmos, acreditamos que as defasagens curriculares devem ser supridas pela formação continuada. A preocupação com essa questão nos leva a refletir sobre a educação que os surdos estão e estarão recebendo nas escolas inclusivas.

Para viabilizar o dia a dia dos nossos surdos em sala de aula, fica aqui a nossa provocação e indagação sobre a nossa escolha profissional. Esta é uma profissão que há tempos vem perdendo seu valor não somente ético, mas moral e financeiro, portanto, os desafios vão na contramão, e sempre crescentes. Acreditamos que 
na/pela formação docente a pessoa pode ser impulsionada em sua carreira.

Temos certeza que os tempos são outros. O tempo da escola de ontem e de hoje, o tempo da visibilidade e da invisibilidade, o tempo da ruptura de cenário está em nossas mãos.

Os estudos apontam que professores ouvintes ou surdos têm em suas mãos o poder e o dever de inclusão, de dar acessibilidade, quebrar barreiras comunicacionais e que lado a lado os aspectos culturais, históricos e linguísticos possam caminhar, e constituir-se como força da/na transmissão do conhecimento de forma ímpar aos seus pares. A deficiência e a subjetividade não existem fora da história, da cultura, da língua, das relações de poder (PERLIN, 2003).

Diante do exposto, podemos dizer ainda, que a pesquisa nos mostrou que há um esforço de inclusão social e cultural por parte dos docentes, que compreendem que a surdez necessita de espaço para mostrar sua trajetória educacional. Que as pessoas precisam estar abertas e preparadas para aprender diariamente com o surdo sobre suas necessidades. Claro que estamos longe do ideal, mas para alcançar o desejado, o primeiro passo já foi dado, que é o reconhecimento da necessidade que o surdo tem em poder usar sua língua. Portanto, o percurso do ensino em escolas inclusivas, precisa passar pela conscientização dos responsáveis pela qualidade de ensino, ou seja, uma ação de toda a sociedade.

\section{Referências}

BOURDIEU, P. \& PASSERON, J. C. A reprodução: elementos para uma teoria do sistema de ensino. Rio de Janeiro: Francisco Alves, 1975.

BRASIL. Constituição da República Federativa do Brasil. Promulgada em 5 de outubro de 1988. Disponível em: http://www.planalto.gov.br/ccivil_03/ constituicao/constituicaocompilado.htm. Acesso em 15 de janeiro de 2017.

BRASIL. Lei 10.436. Dispõe sobre a Língua Brasileira de Sinais - Libras, 24 de abril de 2002.

BRASIL. Ministério da Educação e Cultura. Lei no 9.394, de 20 de dezembro de 1996. Estabelece as Diretrizes e Bases da Educação Nacional. Diário Oficial da União. Seção 1. 
BRASIL. Decreto 5626, de 22 de dezembro de 2005. Regulamenta a Lei n. 10436 Disponível em http://www.planalto.gov.br/ccivil_03/_ato2004-2006/2005/ decreto/d5626.htm. Acesso em 15 de janeiro de 2017

BRASIL. Secretaria de Educação Fundamental. Parâmetros Curriculares Nacionais. Brasília: MEC/SEF, 2000.

BRITO, L.F. Por uma gramática de Língua de Sinais. Rio de Janeiro: Tempo Brasileiro, 1996.

BUENO, J. G. S. Crianças com necessidades educativas especiais, política educacional e a formação de professores: generalistas ou especialistas. Revista Brasileira de Educação Especial, v. 3, n. 5, 1999.

CARVAlHO, P.V. de. Breve História dos Surdos no Mundo. Lisboa: Surd'Universo, 2007.

CURY, C.R.J. Os fora de série na escola. Campinas: Autores Associados, 2005.

DELORS, J. (org). Educação: um tesouro a descobrir. São Paulo: Cortez, 1998.

GLAT, R. Capacitação de professores: pré-requisito para uma escola aberta à diversidade. Revista Souza Marques, v. I, 2000, p. 16-23.

LACERDA, C.B.F Os professores dialógicos entre alunos surdos e educador ouvinte: examinando a construção de conhecimento. Campinas: Unicamp, 2000.

LOPES, M.C. O direito de aprender na escola de surdos. In: LOPES, M.C. THOMA, A. da S. (orgs) A invenção da surdez II: espaços e tempos de aprendizagem na educação de surdos. Santa Cruz do Sul: Ed. EdUNISC, 2006.

LOPES, M.C. Surdez \& Educação. Belo Horizonte: Ed. Autêntica, 2007

LUNARDI, M. L. A produção da anormalidade surda nos discursos da educação especial. 2003. Tese de Doutorado em Educação. Porto Alegre: UFRGS, 2003.

MAZZOTTA, M.J.S. Educação escolar: comum ou especial? São Paulo: Pioneira, 1998.

MAZZOTTA, M.J.S. Trabalho docente e formação de professores de educação especial. São Paulo: EPU, 1993. 
MORIN, E. A cabeça bem feita: repensar a reforma, reformar o pensamento. Tradução Eloá Jacobina, 7 ed. Rio de Janeiro: Bertrand Brasil, 2002.

MOURA, M.C. O surdo: caminhos para uma nova identidade. Rio de Janeiro: Ed. Revinter, 2000.

NÓVOA, A. Profissão professor. Porto: Porto Ed, 1995.

PERLIN, G. T.T. O ser e o estar sendo surdos: alteridade, diferença e identidade. Porto Alegre: UFRS, 2003. Tese de doutorado em Educação.

PIAGET, J. Para onde vai a educação? Rio de Janeiro: José Olympio, 1973.

REILY, M.H. Nas margens dos manuscritos e da vida: representações de deficientes em iluminuras medievais. In: Reunião anual da ANPED, 31, Caxambu: ANPED, 2009.

ROCHA, L.A.C. A formação docente para o trabalho com alunos surdos em escolas regulares. São Paulo: Cadernos de Educação. v. 16. n. 33, jul.-dez., 2017.

SANTOS, M.P. de (org). Inclusão em educação: culturas, políticas e práticas. 2.ed. São Paulo: Cortez, 2008.

UNESCO - Organização das Nações Unidas para a Educação, Ciência e Cultura / Ministério da Educação e Ciência da Espanha / Coordenadoria Nacional para a Integração da Pessoa Portadora de Deficiência - Corde. Declaração de Salamanca e linha de ação sobre necessidades educativas especiais. Brasília, 1994.

WERNECK, C. Ninguém mais vai ser bonzinho na sociedade inclusiva. 3.ed. Rio de Janeiro: WVA, 2009.

Submetido em: 30-9-2018

Aceito em: 23-11-2018 